Review Article

\title{
Significance of Hygienic processing of Milk and Dairy products
}

\author{
Mahendra Pal1, Mridula Devrani1 and Suneeta Pinto ${ }^{2}$ \\ INarayan Consultancy on Veterinary Public Health and Microbiology, 4 Aangan, Jagnath Ganesh Dairy Road, Anand, India \\ ${ }^{2}$ Department of Dairy Technology, SMS College of Dairy Science, Anand Agricultural University, Anand-388110, India
}

\section{Article Info}

\section{*Corresponding author:}

\section{Mahendra Pal}

Founder Director of Narayan Consultancy of Veterinary Public Health and Microbiology

4, Aangan, Ganesh Dairy Road

Anand-38001, India

E-mail: palmahendra2@gmail.com

Received: August 24, 2018

Accepted: August 28, 2018

Published: September 3, 2018

Citation: Pal $M$, Devrani $M$, Pinto S. Significance of Hygienic processing of Milk and Dairy products. Madridge J Food Technol. 2018; 3(2): 132-136. doi: $10.18689 / \mathrm{mjft}-1000120$

Copyright: @ 2018 The Author(s). This work is licensed under a Creative Commons Attribution 4.0 International License, which permits unrestricted use, distribution, and reproduction in any medium, provided the original work is properly cited.

Published by Madridge Publishers

\begin{abstract}
The food production chain has become more complex, providing a greater opportunity for the contamination and growth of microbes. Milk is an important component of a healthy and well balanced diet due to its nutritional richness. Currently, around 800 to 1000 milk products of different types are prepared worldwide. A wide variety of dairy foods, such as cheese, butter, ice cream, yoghurt, and dry milk powder, are consumed worldwide including India. Approximately, 50 to $55 \%$ of milk in India is used to manufacture a large range of traditional dairy products. India is the largest producers as well as consumers of dairy products. The microbial contamination of milk and milk products can occur through various routes, such as environment, handlers, equipments, and packaging materials. The milk and milk products intended for human must be free from pathogens, such as Campylobacter jejuni, Escherichia coli O157H:7, Listeria monocyogenes, Salmonella, Stahylococcus aureus, and Yersinia enterocolitica, which produce serious disease especially among children, elderly, pregnant women, and immunocompromised individuals. It is pertinent to mention that no dairy products should be made from raw milk that serves as source of microbial contamination. The improper cleaning and poor sanitation of dairy equipments may lead to food poisoning due to contamination by pathogens. Since food safety is an increasing global public health issue, it is emphasized to implement the good hygienic practice (GHP), good manufacturing practice (GMP), and hazards analysis and critical control point (HACCP) in dairy industries to reduce the level of microbial contamination. It is imperative that strict hygienic measures must be adopted during the preparation, storage, and delivery of a variety of milk products. In addition, the education of food handlers on the principles of milk hygiene should be imparted for the production of superior quality of dairy products, which can be safely consumed by people.
\end{abstract}

Keywords: Dairy industry; Food handler; Hygienic production; Milk; Milk products; Public Health.

\section{Introduction}

It is believed that consumption of milk and dairy foods started around $6000 \mathrm{BC}$. The milk and milk products had been the choicest item of food in the dietary of Indian people from the time immemorial. There has been a phenomenon growth of dairy industries throughout the world including India. Dairying has become an important secondary source of income for millions of rural households engaged in agriculture [1]. With 191 million cattle and 109 million buffaloes, India accounts for 30.3 per cent of the global bovine population. The country also tops in world milk output, with an estimated 155.5 million tonnes output in 2015-16 [2]. The present per capita availability of milk is around 337 grams per day. Presently, India ranks first in global milk production accounting for over $13 \%$ of the world's 
total milk production. It is estimated that about $40 \%$ of total world milk production is converted into cheese. Though milk and milk products are important source of energy for our body function, sometimes, it may get contaminated either by spoilage producing microbes (Achromobacter, Acinetobacter, Alcaligenes, Bacillus, Clostridium, Enterobacter, Flavobacterium, Micrococcus, Pseudomonas, Serratia, Alternaria, Aspergillus, Candida, Cladosporium, Geotrichum, Mucor, Penicillium, Rhizopus, Rhodotorula, Saccahromyces) or disease causing pathogens (Staphylococcus aureus, Escherichia coli 0157: H7, Salmonella, Campylobacter jejuni, Yersinia enterocolitica, Listeria monocytogeneses) [3]. The contamination of milk and dairy products by microbial agents is a worldwide problem, and can occur at any stage of food chain from farm to fork. The presence of microbes in daily products are undesirable, at these render the milk products of inferior quality. It is well recognized that hygiene plays a pivotal role in the safety of foods and hence, protects the health of the consumer. Therefore, hygienic practices should be meticulously followed to ensure that food is safe, wholesome, and will not cause any harm to the consumer, and also will not allow the growth or survival of spoilage microorganisms as well disease causing pathogens during production, processing, handling, packaging, storage, and distribution [1]. It is mentioned that cleaning and sanitation of milk and milk products contact surfaces contribute around 60 $\%$ of the total contamination in a dairy plant [4]. At room temperature, milk can be stored only for 3 hours immediately after milking. The shelf life of milk can be extended to 24 hours by cooling to $5^{\circ} \mathrm{C}$. Its shelf life is further extended to 4 to 7 days by pasteurization, which was invented by French Scientist Louis Pasture in 1864 [1]. By UHT treatment, the shelf-life of milk is extended to few months. Yoghurt has keeping quality of 1-2 days at ambient temperature, and 1 week under refrigerated condition. It is important to mention that standard pasteurization helps the microbial spoilage of dairy products. Many types of products, such as cream, butter, ice cream, cheese, milk powder, yoghurt, and others are prepared from the milk of dairy animals, predominantly from cow's milk [3]. However, in Asian countries like India, buffalo milk is also frequently employed for manufacturing a variety of products. The maintenance of high standard of sanitation during the processing, packaging, and distribution of milk products; and strict hygienic practices by food handlers are main actions, which are required to produce a good quality of dairy products, which are safe to human health The present communication is aimed to describe the processing of various dairy products in hygienic manner in order to obtain good quality with long shelf life and excellent consumer safety.

\section{Hygienic aspects of milk}

Milk may be defined as the whole, fresh, clean, lacteal secretion obtained by the complete milking of one or more healthy milch animals, excluding that obtained within 15 days before or 5 days after calving or such periods as may be necessary to render the milk practically colostrum free, and containing the minimum prescribed percentages of milk-fat and milk solids-not-fat. In India, the term "milk" when unqualified, refers to cow or buffalo milk, or combination of two [5].
After reception of raw milk, rapid chilling should be carried out immediately to temperature of $5^{\circ} \mathrm{C}$.

Clean strainer should be used for removal of extraneous matters, such as dirt, hair, dust, dung, plastics, broken glass pieces, nails, wire, pant leaves, fly etc. Proper maintenance of pasteurization temperature is required. No milk residues should be left after cleaning- in- place is done. Proper sanitization of crates is very essential. It is imperative to avoid rupturing of milk pouches during handling. Control of air temperature in the coolers should be maintained. It is suggested that hot water must be used for proper flushing of vending machine [1]. Many pathogens survive in environment for long periods of time, and can enter in milk from various sources. It is important to mention that about 4 to $13 \%$ raw milk samples from grade A dairies contained bacterial pathogens.

\section{Hygienic aspects of cream}

Cream is milk product, which is prepared from the milk of cow or buffalo. It is good source of milk fat, and also fat soluble vitamins such as $A, D, E$ and $K$ [1]. Cream consists of a concentration of the fat in milk, with the fat existing mainly as globules protected by a membrane. As such, cream can have a variety of compositions and is normally defined according to fat content or function. Fat content may range from 10 per cent (half-cream) to 80 per cent plus (plastic cream) [6].

It is incredibly important to make use of high-quality of milk to manufacture cream. Therefore, sufficient heat treatment of milk should be done. Final cooling of cream in tank to $5^{\circ} \mathrm{C}$ is required. Proper storage of cream at $5^{\circ} \mathrm{C}$ or less is very essential [1].

\section{Hygienic aspects of butter}

Butter is acknowledged as one of the oldest dairy products made from milk. It is mentioned that Egyptians used the butter approximately 3000 B.C. [7]. In India, butter is used as food commodity and also in connection with religious ceremonies. Butter was one of the first dairy products manufactured by humans, and has been traded internationally since the 14 th century. Butter can be defined as a fat concentrate, which is obtained by churning cream, gathering the fat into a compact mass and then working it [5]. According to the Prevention of Food Adulteration Rules 1976, the table /creamery butter should contain not less than $80 \%$ fat, $3 \%$ common salt, and $1.5 \%$ curd. Diacetyl, which is added as a flavouring agent, should not exceed 4 ppm [5]. Salt enhances the flavour and improves the keeping quality of butter. The butter is very rich in fat and fat soluble vitamins such as $A, D, E$, and $K$. The butter is a water-inoil emulsion, and essentially the fat of the milk. It is usually prepared from sweet cream and it is salted. However, it can also be made from acidulated or bacteriologically soured cream, and salt less butter is also available. The principal constituents of normal salted butter are fat, water, salt as well as protein, calcium and phosphorus [8]. Butter can be used in several ways. Maximum consumption of butter is observed in the baking and confectionary industries worldwide. Many baking products such as cakes, cookies, pastries, biscuits, breads, pies, crumbles, tartlets etc. are manufactured with 
butter. In many countries of the world, butter is applied on the slices of bread for direct consumption during breakfast. The preparation of sauces also requires butter. Butter is used as a cooking medium. In addition, butter is also employed to manufacture ice cream, butter oil, and ghee (India) [5]. Buffalo milk containing about 7 to $8 \%$ fat gives more butter as compared to cow milk, which has approximately 3.5 to $4.5 \%$ fat [9]. In Canada and USA, salted butter is relished by people whereas Europeans prefer unsalted (fresh) butter. However, in rural areas of India, Desi butter, which does not contain any flavouring, colouring agents, and added salt, is generally liked by people particularly the children [9].

Proper pasteurization of cream is fundamental to destroy the microbes. Multiplication of psychrotrops can be prevented by efficient cooling at low temperature $\left(3-5^{\circ} \mathrm{C}\right)$. Just prior to use, churn should be sanitized with $200 \mathrm{mg} /$ liter chlorine solution. Most of the organisms in cream are drained in buttermilk but molds are retained in the butter. In order to control the moulds, regular cleaning of butter churn is crucial. Blending should be avoided as it increases the microbial count in butter [9]. In addition, use of clean and sanitized packing material, proper cleaning of surface of packing room, storage of cream at low temperature, good ventilation in storage room, prevention of aerial contamination, maintenance of high standard of hygiene in butter packing, and hygienic practices by food handler are key measures, which are required to produce a good quality of butter, which is safe to human health [9]. Further, it is vital to point out that the hygienic storage of butter at -25 to $-29^{\circ} \mathrm{C}$ can maintain the keeping quality of the product for at least one year [10].

\section{Hygienic aspects of ice cream}

Among the several dairy products, ice cream is most widely consumed frozen desert both in developed and developing countries of the world. It is a rich source of fat, protein, calcium, phosphorus, and vitamins, such as $A, E$, riboflavin, and niacin [1]. According to the FSSAI (2006), ice cream, kulfi, chocolate ice cream or softy ice cream means the product obtained by freezing a pasteurized mix prepared from milk and/or other products derived from milk with or without the addition of nutritive sweetening agents, fruit and fruit products, eggs and egg products, coffee, cocoa, chocolate, condiments, spices, ginger and nuts, and it may also contain bakery products, such as cake or cookies as a separate layer and/or coating. These products may be frozen hard or frozen to a soft consistency so that they shall have pleasant taste, and smell free from off flavour and rancidity.

Sugar can be a major source of moulds, yeasts, and bacterial spores. It is prudent to use the sugar having mesophillic count of less than 20 and yeasts and molds count should be less than 1.0 per gram. Fresh and frozen fruits should be examined for yeasts. Nuts may contain moulds and therefore, nuts should be sterilized with ethylene oxide and $\mathrm{CO}_{2}$ at the ratio of 1:9. Air can be potential source of organisms and hence, only filtered air should be incorporated in ice cream. Packaging materials should be effectively sanitized before use, since they are good source of fungi.

\section{Hygienic aspects of cheese}

Cheese is a highly nutritious milk product of good keeping quality, and contains protein, fat, calcium, phosphorus, riboflavin, and other vitamins. Presently, over 200 types of cheese are available in the world. It a fermented dairy product, and traditionally forms part of the Mediterranean diet [11]. Cheese means the ripened or un-ripened soft or semi-hard, hard, and extra hard product, which may be coated with food grade waxes or poly film, and in which the whey protein / casein ratio does not exceed that of milk. Cheese is obtained by coagulating wholly or partly milk and/or products obtained from milk through the action of non-animal rennet or other suitable coagulating agents and by partially draining the whey resulting from such coagulation and/or processing techniques involving coagulation of milk and/or products obtained from milk which give a final product with similar physical, chemical and organoleptic characteristics. The product may contain starter cultures of harmless lactic acid and/or flavour producing bacteria and cultures of other harmless microorganisms, safe and suitable enzymes and sodium chloride. It may be in the form of blocks, slices, cut, shredded or grated cheese [12].

High quality of raw milk should be used. Bactofugation of raw milk at 10,000 to 20,000 rpm can reduce bacterial count by 99.98 per cent. Good, active starter cultures should be added @1 per cent to milk and care must be taken to avoid microbial contamination. Pressing of cheese is to be supervised by experienced personnel. Pipelines and other utensils should be thoroughly cleaned and sanitized every day. These measures are proved very effective to produce good quality of cheese [10].

\section{Hygienic aspects of milk powder}

Milk powder means the product obtained by partial removal of water from milk of cow and/or buffalo. The fat and/ or protein content of the milk may be adjusted by addition and/or withdrawal of milk constituents in such a way as not to alter the whey protein to casein ratio of the milk being adjusted. It shall be of uniform colour, and shall have pleasant taste and flavor. It should be free from off flavour and rancidity and also be free from vegetable oil/ fat, mineral oil, thickening agents, added flavor, and sweetening agent [12].

It is important to state that high microbial quality of raw milk must be used for the manufacturing of dried milk powder. Evaporators should be properly cleaned and sanitized as they may act as potential source of microbial contamination. Roller drying is found effective as it kills most of the microbes. It is compulsory to maintain sanitary conditions in drying room to prevent the contamination of milk powder. Filtered air should be supplied for the driers, conveyers, cooling, and air sweeping processes. Therefore, filter pads need periodical cleaning to remove the accumulated dust. All vacuum pans, pipelines, concentration tank, packaging room, and storage container must be thoroughly cleaned and sanitized These steps are necessary for the production of high quality of milk powder, which has long shelf life $[13,14]$. 


\section{Hygienic aspects of yoghurt}

Yoghurt, a fermented milk product, is an important source of protein, calcium, phosphorus, potassium, magnesium, potassium, riboflavin, vitamin $A$, and folic acid; and helps to maintain a healthy gut and immune system. Several types of stirred yoghurt are available in the market, which vary in fat, sugar, texture, flavor, and type of fruits. Yeasts and moulds are mainly responsible for the spoilage of yoghurt, as they are not affected by low $\mathrm{pH}$. It is essential that microbiological specifications should be applied to some additive used in the manufacture of yoghurt.

Yoghurt means a coagulated product obtained from toned milk, pasteurized or boiled milk by lactic acid fermentation through Lactobacillus bulgaricus delbruckii var. bulgaricus and Streptococcus thermophillus. It may also contain cultures of Bifidobacterium bifidus and Lactobacillus acidophilus and if added, the declaration to this effect shall be made on the label. The product shall have smooth surface and custard like consistency with no whey separation [12]. Yoghurt should contain fat $(0.0$ to $3.5 \%)$, solids not fat (8.25$14 \%)$, sugar $(0-10 \%)$, and stabilizer $(0.0$ to $2 \%)$. It should be free from any substance foreign to milk, such as animal body fat, vegetable fat, and mineral oil.

It is advised that pasteurized milk should be employed in the preparation of yoghurt. Use of raw milk with high microbial load causes a reduction in the quality of yoghurt. As sugar can be the major source of yeasts, moulds and bacterial spores, it is advisable to use the sugar having mesophilic count of less than 20, and yeasts and moulds count less than 1.0 per gram. It is emphasized that fresh and frozen fruits should not contain yeasts. The skim milk powder and chocolate should be of high microbiological quality. The utensils used in the manufacturer of yoghurt should be properly cleaned and washed, as unclean or inadequately washed utensils are responsible for the high total bacterial count. Tables, floors and other sites in the dairy plant should be kept in good sanitary condition, as they are a potential source of yeasts and moulds. Flavouring agents should be handled, and stored in cool and dry condition to avoid contamination. Potable soft water should be used in dairy plant as contaminated water can serve as vehicle for spoilage organisms. It is emphasized that dairy plant should be inspected daily, and microbial tests should be carried out periodically by using swab and rinse methods. Aqueous solution of colour made in boiled water is safe to add in the final product. The packaging materials must be effectively sanitized before use, since they act as good source of fungi. Proper packaging under hygienic conditions can enhance the shelf life of the product. Good hygienic practice and good manufacturing practice can reduce the level of microbial contamination. It is imperative that strict hygienic measures must be adopted during the preparation, storage, and distribution of milk products including yoghurt [4].

\section{Microbiological quality of milk and milk products}

Microbiological standards have been proposed from time-to-time to ensure food safety [1]. When a food poses a health hazard, microbiological examination should be made, hazards identified and specifications established. The foodborne pathogens found in milk may cause various symptoms, such as nausea, vomiting, fever, loose stools, and in severe cases, death [15]. Various outbreaks of food-borne illness associated with the consumption of dairy products have been documented in literature $[9,13,16,17]$. Diseases caused by consumption of contaminated milk and milk products pose a serious threat particularly to the infants, pregnant women, elderly people, and immunocompromised persons [1]. Standards for specific pathogens have been proposed either by fixing maximum permissible limits per unit (gram, $\mathrm{ml}$ or $\mathrm{cm} 2$ ) or by testing presence or absence of the organism in a given unit of food e.g. Staphylococcus aureus or Salmomella spp., respectively. Generally, the decisions on the acceptability of food lots are based on the examination of one or few samples taken from the batch. PFA specifies the maximum upper limit of microflora in pasteurized milk as 30,000 cfu/g [18]. Further, PFA specifies the limits for coliform as absent per 0.1g, for Escherichia coli, Staphylococcus aureus, yeast and moulds, anaerobic spore former, Listeria monocytogenes as absent per gram for each,and for Shigella and Salmonella as absent per $25 \mathrm{~g}$ of pasteurized milk. Pathogens, such as Listeria monocytogense, Salmonella, Shigella, and Escherichia coli must be absent in dry milk powder [19].

The dairy animals, milking machines, containers, utensils, water, air, soil, flies, rodents, packaging material etc. are the major sources of microorganisms that degrade the quality of milk $[20,21]$. The higher percentage of microflora in raw milk may be due to contamination from the animal and unhygienic milking procedures or equipment leading to entry of pathogens from dairy utensils and milk contact surfaces (exterior of the infected udder and adjacent areas) [22,23]. Moreover, storage conditions of raw milk, the health status of dairy animals, and nature of their feed are also crucial in determining the composition of their microflora [24]. It is pertinent to reveal that pasteurization, which was invented by Lois Pasteur at a time when millions of people became ill and died following the ingestion of raw milk, is a very important practical preventive approach from a public health point of view to guarantee safety of milk to consumers [1]. It is imperative to monitor the microbiological quality of raw milk and milk products from food safety point of view.

\section{Conclusion}

Milk has become an increasingly important source of protein, and other elements necessary for the maintenance of healthy body, and constitutes an important food component for a large section of the world population. It can also serve as vehicle for many types of microbes, which can either cause spoilage or produce disease. The quality of milk is of major concern to the food processors, consumers, and public health authorities. Proper packaging and storage under strict hygienic conditions can undoubtedly enhance the shelf life of dairy products. It is recommended that properly pasteurized milk should be employed in the preparation of various milk products intended for human consumption. Provision of safe, 
wholesome and acceptable milk and milk products, through control of contamination is essential from food safety point of view. It is pertinent to frame strategies to prevent the microbial contamination of dairy products at all stages of the food supply chain.

\section{Acknowledgements}

The authors wish to thanks Prof. Dr. R. K. Narayan for critical editing of the manuscript and Anubha for rendering computer help. This paper is dedicated in the memory of Shri Atal Bihari Yajpayee the former Prime Minister of India who was a recipient of Bharat Ratan, the highest civilian award. He was a great philosopher, thinker, statement, politician, and administrator besides an honest, generous, kind and noble man.

\section{Conflict of interest}

Author declares that there is no conflicts of interest.

\section{References}

1. Pal M. Hygienic aspects of various milk products. Ph.D. Lecture Notes. Faculty of Veterinary Medicine, Addis Ababa University, Debre Zeit, Ethiopia. 2012; 1-7.

2. Narware M. Cattle breeding policy: Desi breed conservation should not be at expense of farmers, milk output. Dairy Times. 2018; 3: 34-35.

3. Pal $M$, Jadhav VJ. Microbial contamination of various milk products. Beverage and Food World. 2013; 40: 43-44.

4. Pal M, Mahendra R. Sanitation in Food Establishments. LAMBERT Academic Publishing. Saarbruchen, Germany, 2015.

5. De S. Outlines of Dairy Technology. Oxford University Press. New Delhi, India, 2001.

6. Towler C. Developments in Cream Separation and Processing. In: Robinson RK (eds). Robinson: Modern Dairy Technology. Springer, Boston, MA, USA, 1994.

7. Jay JM, Loessner MJ, Golden DA. Modern Food Microbiology. $7^{\text {th. Ed. }}$ Springer Science, USA, 2005.

8. Van Ruth SM, Koot A, Akkermans W, et al. Butter and butter oil classification by PTR-MS. European Food Research and Technology. 2008; 227: 307-317. doi: 10.1007/s00217-007-0724-7
9. Pal $\mathrm{M}$, Awel $\mathrm{H}$. Public health significance of Listeria monocytogenese in milk and milk products. Journal of Veterinary Public Health. 2014a; 12: 1-5.

10. Pal M, Feleke A, Geloye $M$, Waktole $H$, Deressa A. Microbial quality and safety of cheese. Beverage and Food World. 2014b; 41: 32-33.

11. Hinrichs J. Mediterranean milk and milk products. European Journal of Nutrition. 2014; 43(Suppl. 1): i12-i17. doi: 10.1007/s00394-004-1104-8

12. Food Safety and Standard Regulations, 2010

13. Pal M, Mahendra R. Escherichia coli 0157:H7: An emerging bacterial zoonotic food borne pathogen of global significance. International Journal of Interdisciplinary and Multidisciplinary Studies. 2016; 4: 1-4.

14. Pal M, Tesfaye S, Wedegebril S. Hygienic and microbiological aspects of ice cream. Beverage and World Food. 2012b; 39: 42-43.

15. Agarwal A, Awasthi V, Dua A, Ganguly S, Garg V, Marwaha SS. Microbiological profile of milk: Impact of household practices. Indian Journal of Public Health. 2012; 56(1): 88-94. doi: 10.4103/0019-557X.96984

16. Silva $R$, Cruz AG, Faria JA, et al. Pasteurized milk: Efficiency of pasteurization and its microbiological conditions in Brazil. Foodborne Pathog Dis. 2010; 7: 217-219. doi: 10.1089/fpd.2009.0332

17. Pal M. Campylobacter jejuni: An emerging foodborne pathogen of global significance. Journal of Experimental Chemistry. 2017; 4: 1-4.

18. The Prevention of Food Adulteration Act, Microbiological parameters for milk products. The prevention of food adulteration (third amendment) rules, 2009; 349-350.

19. Pal M, Alemu J, Mulu S, Karanfil O, Parmar BC, Nayak JB. Microbial and hygienic aspects of dry milk powder. Beverage and Food World. 2016b; 43: 28-31.

20. Burton $\mathrm{H}$. Microbiological aspects of pasteurized milk. Bulletin International Dairy Federation. 1986; 200: 9-14.

21. Pal $M$, Tefera $M$, Tasew $A$, Jergerfa $T$, Deressa $A$. Hygienic and microbiological quality of yoghurt. Beverage and Food World. 2015; 42: 25-27.

22. Chye FY, Abdullah A, Ayob MK. Bacteriological quality and safety of raw milk in Malaysia. Food Microbiology. 2004; 21: 535-541. doi: 10.1016/j. fm.2003.11.007

23. Chatterjee SN, Bhattacharjee I, Chatterjee SK, Chandra G. Microbiological examination of milk in Tarakeswar, India with special reference to coliforms. Afr J Biotechnol. 2006; 5: 1363-1385.

24. Lafarge V, Ogier JC, Girard V, et al. Raw cow milk bacterial population shifts attributable to refrigeration. Appl Environ Microbiol. 2004; 70(9): 5644-5650. doi: 10.1128/AEM.70.9.5644-5650.2004 